\title{
Basic Dye Adsorption on Low Cost Biopolymer: Kinetic And Equilibrium Studies
}

\author{
Mona A. Shouman ${ }^{1}$, Soheir A. Khedr ${ }^{1}$, Amina A. Attia ${ }^{1 *}$ \\ ${ }^{1}$ Surface Chemistry and Catalysis Laboratory, National Research Center, 12622 Dokki, Cairo, Egypt.
}

\begin{abstract}
The adsorption behavior of crystal violet, on chitosan has been studied extensively. A series of experiments were conducted in a batch system to evaluate the effect of the system variables i.e. initial pH, initial dye concentration, contact time and temperature. The adsorption facts were analyzed by using Langmuir, Freundlich, Temkin and Dubinin-Radushkveich isotherm models. The equilibrium data were best represented by Langmuir isotherm model showing maximum monolayer adsorption capacity $28.5 \mathrm{mg} / \mathrm{g}$. The kinetic data were fitted to pseudo - second order kinetic model which shows that intraparticle diffusion has a significant role in the adsorption process. The thermodynamics of crystal violet onto chitosan indicate its spontaneous and endothermic nature. The adsorbent was analyzed by $\mathrm{N}_{2}$ adsorption - desorption technique, FTIR, SEM, and TG - DTG. Chitosan was shown to be promising adsorbent for the removal of dyes from aqueous solutions.

Keywords: Adsorption, Chitosan, Diffusion, Dye, Kinetic study
\end{abstract}

\section{Introduction}

Many industries, such as textile, paper, plastics and dyestuffs, consume substantial volume of water, and also use chemicals and dyes during manufacturing to color their products. As results, they generate a considerable amount of polluted waste-water [1]. The discharge of dyes in the environment is worrying for both toxicological and esthetical reasons [2]. This specific type of pollution is characterized by high biochemical oxygen demand (BOD), chemical oxygen demand (COD), suspended solids (mainly fibers) bad smell, toxicity, and especially color $[3,4]$.

During the past three decades, several waste water treatment methods have been reported and attempts for the removal of pollutants from textile pulps and paper mill effluents have been carried out. This technologies can be divided into three main categories: (i) conventional methods included coagulation/ flocculation, biodegradation and adsorption [5, 6] (ii) established recovery processes [e.g.: oxidation, membrane separation] and iii) emerging removal methods (e.g. Biomass, selective bioadsorption) [7]. It is now recognized that adsorption using low- cost adsorbents is an effective and economic method for water decontamination. Biopolymers have received a great deal of attention due to the fact that they represent renewable resources and more environmental friendly than commercial materials.

Special attention has been given to a natural amino polysaccharide called Chitosan. Chitosan is a partially acetylated glucosamine biopolymer, which mainly results from the deaetylation of chitin, which is a major component of arthropod and crustacean shells such as lobsters, shrimps, crabs and cuttlefishes [8]. As shown from Figure 1, chitosan has three types of reactive functional groups, an amino group as well as both primary and secondary hydroxyl groups at the C-2, C-3 and C-6 positions, respectively. Its advantage over other polysaccharides is that its chemical structure allows specific modifications, especially at the C-2 position. These functional groups allow direct substitution reactions and chemical modifications, yielding numerous useful materials for different domains of application [9]. Chitosan is known as an ideal support material for enzyme immobilization because of its many advantages such as its hydrophilicity, biodegradability, biocompatibility and anti - bacterial property [10]. Chitosan has been widely used as an adsobent for transition metals, organic species $[11,12,13]$ and for dye waste removal from aqueous solutions [14] due to the presence of the amino ($\left.\mathrm{NH}_{2}\right)$ and the hydroxyl (-OH) groups on chitosan chains which serve as the coordination and reaction sites. However, only a limited number of published studies have been found for the use of chitosan as an adsorbent for cationic (basic) dye removal.

Crystal violet, belonging to triphenylmethane group is widely used in animal and veterinary medicine as a biological stain, for identifying the bloody fingerprints [15]. Crystal violet is harmful by inhalation, ingestion and skin contact, and has also been found to cause cancer and severe eye irritation to human beings $[16,17]$. It is poorly degraded as recalcitrant molecule by microbial enzymes, and can persist in a variety of environments.

In the present work, the adsorption characteristics of crystal violet were investigated using chitosan (85\% deacetylated) as an adsorbent from aqueous solution. The texture characterization, FTIR, TG-DTG, SEM were also carried out. The equilibrium kinetics and thermodynamic data of the adsorption process were 
evaluated to study the adsorption mechanism of crystal violet onto chitosan. The results of this work are anticipated to be essential to ensuring the practical use of chitosan in color removal from waste water.

\subsection{Adsorbent}

\section{Experimental}

The raw material, exoskeleton of fresh shrimp shell for preparation of chitin and chitosan was obtained from fish markets. The shells and heads of fresh shrimp were thoroughly and repeatedly washed in water and sun dried. The raw material was completely immersed (steel container) in $1.25 \mathrm{~mol} / \mathrm{L} \mathrm{NaOH}$ solution and boiled for one hour for deprotonisation. After cooling, the alkali was drained off and washed repeatedly with ionized water to obtain neutral $\mathrm{pH}$. The contents were transferred in a plastic container and $5 \% \mathrm{HCL}$ was added and allowed to act for one hour to remove $\mathrm{CaCO}_{3}[18,19]$. The acid was decanted and repeatedly washed with water and then with ionized water. The excess water from the chitin obtained is removed by squeezing in a sterile lint cloth and air dried. The resulting insoluble solid (chitin) was deacetylated in $5 \mathrm{~N} \mathrm{NaOH}$ at $110^{\circ} \mathrm{C}$ for $3 \mathrm{~h}$. The $\mathrm{NaOH}$ was quickly drained off and the content was repeatedly washed with water and finally with deionized water. The prepared chitosan flakes was sterilized with ethylene oxide and packed in pre autoclaved polyethylene containers. (Figure 1)

The deactylation degree was determined and calculated from the following relationships, by using FTIR spectrophotometer [19].

$$
\mathrm{DD}=100-\frac{\mathrm{A}_{1660 \mathrm{~cm}^{-1}} / \mathrm{A}_{3650 \mathrm{~cm}-1}}{1.33} \times 100
$$

\subsection{Adsorbate}

Crystal violet dye ( $\mathrm{CI}=42555$, chemical formula $\mathrm{C}_{25} \mathrm{H}_{30} \mathrm{~N}_{3} \mathrm{Cl}$, and $\left.\lambda_{\max }=586 \mathrm{~mm}\right)$ was purchased from Sigma Chemical Company USA, and used without chemical purification (Figure 2). The stock solution was prepared by dissolving an accurate weighed $250 \mathrm{mg}$ of dye in one liter of distilled water. The experimental solutions of desired concentrations were obtained by successive dilutions with double distilled water.

\subsection{Characterization of the Adsorbent}

The morphology of chitosan was investigated using scanning electron microscope (JEOL JMS- 840). FTIR spectra of chitosan was obtained by a Perkin - Elmer FTIR spectrophotometer, model Sepectrum 1000, to analyse the surface functional groups of chitosan in the range of $4000-400 \mathrm{~cm}^{-1}$. The structure of chitosan was investigated by $\mathrm{N}_{2}$ adsorption isotherms at $77 \mathrm{~K}$ with Qutachrome NOVA Automated Gas sorption, version 1.12. Prepared chitosan was subjected to thermogravimetric analysis TG/DTA using Perkin Elmer Diamond analyzer instrument. Runs were carried out at linear heating rate $10^{\circ} \mathrm{C} / \mathrm{min}$ from 50 to $1000^{\circ} \mathrm{C}$ under high purity nitrogen. Thermal drying method was used in the determination of moisture content of the samples. $1.0 \mathrm{~g}$ of the dried activated carbons were weighed and placed in an oven and dried at $105^{\circ} \mathrm{C}$ to constant weight for $4 \mathrm{~h}$ according to the method of Rengaraj [20]. To determine the ash content of chitosan, the standard test method for ash contentASTM D2866-94 was used. Some physicochemical properties of chitosan are given in Table 1.

\subsection{Adsorption Experimental Methods and Measurements}

Adsorption isotherm experiments were carried out by agitating $(0.15 \mathrm{~g})$ adsorbent in $100 \mathrm{ml}$ dye solution having concentrations ranging from $10-60 \mathrm{mg} / \mathrm{L}$ with $\mathrm{pH}$ of 8 and temperatures (293, 313 and 323K) in $250 \mathrm{ml}$ conical flasks. Shaking was carried out for $24 \mathrm{~h}$ in an incubator shaker operating at $150 \mathrm{rpm}$.

The effect of $\mathrm{pH}$, varied between $2-10$, was studied by adjusting the $\mathrm{pH}$ of the dye solution using dilute $\mathrm{H}_{2} \mathrm{SO}_{4}$ and $\mathrm{NaOH}$ solution. The $\mathrm{pH}$ tests, the dye concentration $(100 \mathrm{mg} / \mathrm{L})$, the adsorption time $(2 \mathrm{~h})$, the stirring speed $(150 \mathrm{rpm})$, and at room temperature were used.

For the adsorption kinetic experiments, the amount of dye adsorption was determined by analyzing the solution at appropriate time intervals. The experiments were conducted by agitating $(1 \mathrm{~g})$ adsorbent in $500 \mathrm{ml}$ dye solution at three different initial concentration $(75,150$ and $250 \mathrm{mg} / \mathrm{L})$ with $\mathrm{pH}$ of 8 at room temperature in a shaker operating at $150 \mathrm{rpm}$.

The solution and solid phase were separated by centrifugation at $150 \mathrm{rpm}$ for five minutes. All basic crystal violet solutions were diluted with distilled water and analyzed using Shimadzu UV - visible 2401 PC spectrophotometer. The dye adsorption capacity at equilibrium $\mathrm{q}_{\mathrm{e}}$ can be calculated from the equation given below

$$
q_{e}=\frac{V\left(C_{o}-C_{e}\right)}{m}
$$


where $C_{o}(\mathrm{mg} / \mathrm{L})$ is the initial dye concentration in liquid phase, $C_{e}(\mathrm{mg} / \mathrm{L})$ denotes the dye concentration in liquid phase at equilibrium, $\mathrm{V}(\mathrm{L})$ represents the total volume of the dye solution, and $\mathrm{m}(\mathrm{g})$ is the mass of the adsorbent.

\subsection{Effect of Initial pH}

\section{Results and Discussion}

The $\mathrm{pH}$ value of the dye solution plays an important role in the entire adsorption process and particularly in adsorption capacities. As revealed from Figure 3, by increasing the $\mathrm{pH}$ value, the dye uptake increases from $5 \%$ to $60 \%$ [21,22]. The maximum uptake was observed at $\mathrm{pH}=8$. This can be explained on the basis that the $\mathrm{pH}$ of the solution affects the surface charge of the adsorbent. The amino groups of chitosan are protonated under acidic conditions according to the following reaction:

$$
\mathrm{R}-\mathrm{NH}_{2}+\mathrm{H}^{+} \rightleftharpoons \mathrm{R}-\mathrm{NH}_{3}^{+}
$$

Also, the cationic dye give positively charged ions when dissolved in water. Reported $\mathrm{pH}_{\mathrm{pzc}}$ value for chitosan was 6.6 [23]. At $\mathrm{pH}$ values lower than the corresponding $\mathrm{pH}_{\mathrm{pzc}}$, the adsorbent will have a net positive charge. Thus, strong coulombic repulsions are developed between the adsorbent and dye. However, at $\mathrm{pH}$ values higher than the corresponding $\mathrm{pH}_{\mathrm{pzc}}$ values of the adsorbent, repulsive forces are weakened since the amino groups of sorbent are deprotonated, thereby resulting in an increased adsorption of dye due to increasing the electrostatic attraction between the positively charged functional groups located on the basic dye and the negatively charged surface of the adsorbent (-OH groups of the chitosan).

\subsection{Effect of Contact Time and Initial Dye Concentration}

Figure 4 shows the adsorption capacity versus the adsorption time at various initial crystal violet concentrations. It indicated that the contact time needed for crystal violet solutions (initial concentrations of 75$250 \mathrm{mg} / \mathrm{L}, \mathrm{pH}=8$ and at room temperature) to reach equilibrium was around $4 \mathrm{~h}$. This observation could be explained by the theory that in the process of dye adsorption, initially the dye molecules have to first encounter the boundary layer effect and then diffuse from the boundary layer film onto adsorbent surface and then finally, they have to diffuse into the porous structure of the adsorbent [24]. Therefore, crystal violet solutions of higher initial concentrations will take relatively longer contact time to attain equilibrium due to higher amount of dye molecules.

As can be seen from Figure 4, the amount of crystal violet adsorbed on chitosan increases with time and, at some point in time, it reaches a constant value beyond which no more crystal violet is further removed from the solution. At this point, the amount of the dye desorbing from chitosan is in a state of dynamic equilibrium with the amount of the dye being adsorbed on chitosan. In other words, fast diffusion onto the external surface of the adsorbent was followed by fast pore diffusion into the intra particle matrix to attain rapid equilibrium. The amount of dye adsorbed at the equilibrium time reflects the maximum adsorption capacity of the adsorbent under those operating conditions. In this study, the adsorption capacity at equilibrium $\left(\mathrm{q}_{\mathrm{e}}\right)$ increased from 12 to $28 \mathrm{mg} / \mathrm{g}$ with an increase in the initial dye concentrations from 75 to $250 \mathrm{mg} / \mathrm{L}$. When the initial concentration increased, the mass transfer driving force would become larger, hence resulting in higher adsorption of crystal violet [25]. A similar trend was also observed for crystal violet adsorption onto modified chitosan [26].

\subsection{Adsorption Kinetic Study}

Adsorption is a time-dependent process, and determining the rate of adsorption is highly important in the design and evaluation of adsorbents in removing dyes from wastewater. The kinetic constants of dye adsorption can be used to optimize the residence condition. The process of dye removal from aqueous phase by a certain adsorbent may be represented by pseudo-first-order kinetics [27] or pseudo-second-order kinetics [28]. The rate constant of adsorption is determined from the first-order rate expression given by Lagergren:

$$
\log \left(q_{e}-q_{t}\right)=\log q_{e}-\frac{k}{2.303} t
$$

where $\mathrm{q}_{\mathrm{e}}$ and $\mathrm{q}_{\mathrm{t}}$ are the amounts of dye adsorbed at equilibrium and at time $\mathrm{t}(\mathrm{min})$, respectively, and $\mathrm{k}$ is the rate constant for first order kinetics. The values of rate constant $\mathrm{k}$, equilibrium adsorption capacity $\mathrm{q}_{\mathrm{e}}$, are calculated from the plots of $\log \left(\mathrm{q}_{\mathrm{e}}-\mathrm{q}_{\mathrm{t}}\right)$ versus $\mathrm{t}$ (Figure not shown). Kinetic data were further examined with the pseudo-second-order kinetic model which is expressed as follows:

$$
\frac{1}{q_{t}}=\frac{1}{K q_{e}^{2}}+\frac{1}{q_{e}} t
$$

Equilibrium adsorption capacity $\mathrm{q}_{\mathrm{e}}$ and second-order rate constants $(\mathrm{K})$ can be determined experimentally from the slope and intercept of plot $t / q_{t}$ versus $t$ (Figure not shown). The $\mathrm{K}$ and $\mathrm{q}_{\mathrm{e}}$ values are listed in Table 2. Based on the correlation coefficients $\left(R^{2}\right)$ the adsorption of crystal violet onto chitosan was 
best described by the pseudo-second-order kinetics. The pseudo - second order model is based on the assumption that the rate controlling step is a chemical sorption involving valance force by sharing or exchange of electrons between adsorbent and adsorbate [29,30].

Intraparticle diffusion model based on the theory proposed by Weber and Morris [31] was tested to identify the diffusion mechanism. It is an empirically found functional relationship, common to the most adsorption processes, where uptake varies almost proportionally with $t^{1 / 2}$ rather than with the contact time $t$. According to this theory:

$q_{t}=k_{p} t^{1 / 2}+C$

where $k_{\mathrm{p}}\left(\mathrm{mg} / \mathrm{g} \min ^{1 / 2}\right)$ is the intraparticle diffusion rate constant.

The intraparticle diffusion model rate constant, $K_{\mathrm{p}}$ is obtained from the slope of the straight line of $q_{t}$ Versus $t^{1 / 2}$ (Figure 5). Values of intercept, $C$, give an idea about the thickness of boundary layer, i.e., larger the intercept, greater is the boundary layer effect [32]. The $R^{2}$ value (Table 2) obtained were high and agreed satisfactorily well for intraparticle diffusion model. The first, sharper portion is the instantaneous adsorption or external surface adsorption. The second portion is the gradual adsorption stage where intraparticle diffusion is the rate limiting. In some cases, the third portion exists, which is the final equilibrium stage where intraparticle diffusion starts to slow down due to the extremely low adsorbate concentrations left in the solutions [33]. As can be seen from Figure 6, the linear line did not pass through the origin and this deviation from the or near saturation might be due to the difference in the mass transfer rate in the initial and final stages of adsorption [34]. This suggested that the overall rate of the adsorption process was controlled by chemisorption which involved valency forces through sharing or exchange of electrons between the sorbent and sorbate [35].

The diffusion coefficients for the intraparticle transport of crystal violet within the pore of chitosan have been calculated at different initial concentrations by employing the following equation [36].

$$
t_{1 / 2}=\frac{0.03 r_{0}^{2}}{D}
$$

where $t^{1 / 2}$ is the time (min) for half adsorption of crystal violet, $r_{o}$ is the radius of the adsorbent particle in $\mathrm{cm}$ and $\mathrm{D}$ is the diffusion coefficient with unit $\mathrm{m}^{2} / \mathrm{min}$. For the calculation of $\mathrm{r}$ value, it was assumed that the solid phase consists of particle which is spherical in nature. For the present study, the pore diffusion coefficient values obtained from equation (7) are given in Table (2). The values of diffusion coefficient for adsorption of crystal violet were found under common experimental conditions to be close to $10^{-18}$. This was attributed to the larger molecular size of the present system, the factor that slows down in diffusion rate. In addition, the present molecules have more complex structures (adsorbate), and therefore its strong interaction with chitosan surface reduces its mobility [37].

\subsection{Equilibrium isotherm studies:}

Adsorption isotherms, or equilibrium data, are the fundamental requirements for the design of adsorption system. Four models, namely, Langmuir, Freundlich, Temkin and Dubinin- Radushkevitch were selected for the biosorption process. Langmuir isotherm assumes monolayer adsorption onto a surface containing a finite number of adsorption sites of uniform strategies of adsorption with no transmigration of adsorbate in the plane of surface [38]. The linear form of Langmuir isotherm equation is given as:

$$
\frac{C_{e}}{q_{e}}=\frac{1}{Q_{0} K_{L}}+\frac{1}{Q_{o}} C_{e}
$$

where $C_{\mathrm{e}}$ is the equilibrium concentration of the adsorbate $(\mathrm{mg} / \mathrm{l}), q_{\mathrm{e}}$ is the amount of adsorbate adsorbed per unit mass of adsorbent $(\mathrm{mg} / \mathrm{g}), Q_{\mathrm{o}}$ and $K_{L}$ are Langmuir constants related to adsorption capacity and rate of adsorption, respectively.

When $C_{e} / q_{e}$ is plotted against $C_{e}$, a straight line with slope of $1 / Q_{o}$ is obtained. The Langmuir constants $\mathrm{Q}_{\mathrm{o}}$ and $\mathrm{K}_{\mathrm{L}}$ were calculated from the slope and intercept of Equation 8. The results are shown in Table 3. From this table, the values of $\mathrm{K}_{\mathrm{L}}$ increased by increasing the temperature from $293 \mathrm{~K}$ to $323 \mathrm{~K}$. The results imply that the affinity of the binding sites for crystal violet is enhanced with temperature.

The Freunlich isotherm is commonly used to describe the adsorption characteristics of multilayer and heterogeneous surfaces. The well - known logarithmic form of the Freundlich isotherm is given by the following equation [39]:

$$
\log q_{e}=\log K_{F}+\left(\frac{1}{n}\right) \log C_{e}
$$

where $C_{\mathrm{e}}$ and $\mathrm{q}_{\mathrm{e}}$ are defined in the same manner as in the Langmuir equation, Freundlich constant, $K_{\mathrm{F}}$, is the adsorption capacity of the adsorbent which can be defined as the adsorption or distribution coefficient and represents the quantity of dye adsorbed onto activated carbon for a unit equilibrium concentration, $1 / n$ is another constant related to surface heterogeneity. In most cases the exponent between $1<\mathrm{n}<10$ shows beneficial adsorption. When $\log \mathrm{q}_{\mathrm{e}}$ is plotted against $\log \mathrm{C}_{\mathrm{e}}$, the constants $\left(K_{\mathrm{F}}\right.$ and $\left.1 / n\right)$ are determined from the slope and intercept (Table 3 ). The results showed that $K_{\mathrm{F}}$ values decreased by increasing the temperature and $\mathrm{n}$ values varied between $1.8-3.6$. 
Temkin and Pyzhev considered the effects of indirect adsorbate/adsorbate interactions on adsorption isotherms. The heat of adsorption of all the molecules in the layer would decrease linearly with coverage due to adsorbate/adsorbate interactions [40]. The Temkin isotherm has been used in the form as follows:

$$
q_{e}=\left(\frac{R T}{b}\right) \ln \left(A C_{e}\right)
$$

where $B=R T / b$ and is related to the heat of adsorption, $R$ is the gas constant $(8.31 \mathrm{~J} / \mathrm{mol} \mathrm{K})$ and $T(\mathrm{~K})$ is the absolute temperature, $A$ is the equilibrium binding constant $(\mathrm{L} / \mathrm{mg})$. A plot of $\mathrm{q}_{\mathrm{e}}$ versus $\ln \mathrm{C}_{\mathrm{e}}$ enables the determination of the constants A and B.

Another popular equation for the analysis of isotherms of a high degree of rectangularity is that proposed by Dubinin and Radushkevich as follow [41]:

$q_{e}=q_{s} \exp \left(-B \varepsilon^{2}\right)$

where $\varepsilon$ can be correlated:

$\varepsilon=R T \ln \left[1+1 / C_{e}\right]$

The constant $B$ gives the mean free energy $E$ of sorption per molecule of the sorbate when it is transferred to the surface of the solid from infinity in the solution and can be computed by using the relationship:

$E=\frac{1}{\sqrt{2 B}}$

The D-R isotherm constants, $B$ and $q_{s}$, calculated from the slope and intercept of the plot between $\ln q_{\mathrm{e}}$ and $\varepsilon 2$ are recorded in Table 3 . The values of porosity factor $(K)$ less than unity indicated a micro- and mesoporous chitosan surface [42]. The values of the mean free energy of sorption (E) calculated from equation 13 indicates that the adsorption process follows a chemical adsorption.

Table 3 summarizes all the constants and correlation coefficients, $R^{2}$ of the four isotherm models used. The Langmuir model yielded the best fit with $R^{2}$ values equal or higher than 0.99 , as compared to the other three models. Conformation of the experimental data into Langmuir isotherm equation indicated the homogeneous nature of chitosan surface, which postulate chemisorptions on a set of well defined localized sorption energies independent of surface coverage and no interaction between adsorbed molecules.[43,44,45].

\subsection{Adsorption thermodynamic study}

Thermodynamic data can be obtained from Langmuir equations. Langmuir constant $\mathrm{K}_{\mathrm{L}}$ is related to the enthalpy of adsorption. Therefore, thermodynamic parameters such as change in standard free energy $\left(\Delta \mathrm{G}^{\circ}\right)$, enthalpy change $\left(\Delta \mathrm{H}^{\circ}\right)$, and entropy change $\left(\Delta \mathrm{S}^{\circ}\right)$ can be determined using the following equations:

$\Delta G_{a d s}=-R T \ln K_{L}$
$\Delta G^{\circ}=\Delta H^{\circ}-T \Delta S^{\circ}$

where $\mathrm{R}(8.31 \mathrm{KJ} / \mathrm{mol}))$ is the gas constant, $\mathrm{T}(\mathrm{K})$ is the absolute temperature, and $\mathrm{K}_{\mathrm{L}}(\mathrm{L} / \mathrm{g})$ is the standard thermodynamic equilibrium constant defined by $\mathrm{q}_{\mathrm{e}} / \mathrm{C}_{\mathrm{e}}$. By plotting a graph of $\ln \mathrm{K}_{\mathrm{L}}$ versus $1 / \mathrm{T}$, the values $\Delta \mathrm{H}^{\circ}$ and $\Delta \mathrm{S}^{\circ}$ can be estimated from the slopes and intercepts (Figure 6). The results of $\Delta \mathrm{G}^{\circ}, \Delta \mathrm{H}^{\circ}$, and $\Delta S^{\circ}$ are listed in Table 4 . The negative values of $\Delta G^{\circ}$ obtained from Equation (15) confirm the feasibility and spontaneous nature of the adsorption of crystal violet onto chitosan. The positive values of $\Delta \mathrm{H}$ confirm the endothermic nature of adsorption process. Moreover, the positive value of $\Delta \mathrm{S}^{\circ}$ shows increased disorder at the solid-solution interface during the adsorption of dye under the experimental conditions. [46].

\subsection{Effect of temperature on adsorption capacity of chitosan}

A study of the temperature dependence of adsorption process gives valuable information about the enthalpy during adsorption. The effect of temperature on the adsorption isotherm was studied by carrying out a series of isotherms at 293, 313 and $323 \mathrm{~K}$ as shown in Figure 7. At temperature 323K, more dye strongly adsorbed by chitosan and thus induced a higher $\mathrm{Q}_{0}$ value (Table 4). This process was endothermic, where increasing the temperature increases the value of $\mathrm{Q}_{0}$.

It was explained that as temperature increased a strong tendency for the formation of monolayer adsorption process occurs $[47,48]$. The increase in temperature would increase the mobility of the large dye ions as well as produce a swelling effect within the internal structure of the chitosan, thus enabling the large dye molecules to penetrate further [49]. Therefore, increasing the temperature largely depends on the chemical interaction between the functional groups on the adsorbent surface and the adsorbate. This leads to an increase in the diffusion rate of the adsorbate into the pores.

\subsection{Characterization of the adsorbent}

Figure 8 represents the FTIR spectra of chitosan $\left(400-4000 \mathrm{~cm}^{-1}\right)$. The wide band at $3414 \mathrm{~cm}^{-1}$ shown in the spectrum is attributed to stretching vibration of hydroxyl group of chitosan. The small band at $3754 \mathrm{~cm}^{-1}$ is due to stretching vibration of N-H groups. The band at $2927 \mathrm{~cm}^{-1}$ is assigned to C-H stretching vibration of polymer backbone. The other band at $1427 \mathrm{~cm}^{-1}$ is due to C-H bending. The bands observed at 1630 and, 1380 
Basic Dye Adsorption On Low Cost Biopolymer: Kinetic And Equilibrium Studies

$\mathrm{cm}^{-1}$ correspond to (-NH stretching vibration). Note in the spectrum of chitosan that the presence of two bands, one at $1154 \mathrm{~cm}^{-1}$ and another at $1036 \mathrm{~cm}^{-1}$, probably indicates stretching vibrations of $\mathrm{C}=\mathrm{O}$ groups. [50, 51].

The SEM micrograph of chitosan is presented in Figure 9, the micrograph showed that the biopolymer has a heterogeneous, smooth and fibril structure. Chitosan is a linear homopolymer of $\beta$ - (1,4)-2- amino -2deoxy - D- glucose, and it is similar to cellulose in morphology.

Figure 10 illustrates the TG-DTG curve of chitosan which represents the stages of decomposition behavior. This figure shows weight losses at three different stages. By heating the material up to $100^{\circ} \mathrm{C}$, the first weight loss $(5.26 \%)$ has been due to the elimination of moisture. The second stage of decomposition from 216$316^{\circ} \mathrm{C}$, corresponds to weight loss of $24.5 \%$ was due to the depolymerization reaction. In the third stage from $316-600^{\circ} \mathrm{C}$, reported a weight loss of $10.08 \%$. Chitosan is thermally stable up to $600^{\circ} \mathrm{C}$ [52].

The BET surface area of chitosan was found to be $131 \mathrm{~m}^{2} / \mathrm{g}$ with total pore volume of $0.108 \mathrm{~cm}^{3} / \mathrm{g}$. The pore size distribution of is shown in Figure 11. The first peak was detected at $18 \AA \hat{\AA}$ which implies to micropore character. The second and third peak occurred at pore diameter ranging between 25 - $43 \AA$ reflects the mesopore character. This mesopore character enhances the mass transfer of the dye to the adsorption sites in the adsorption process.

\section{Conclusion}

In this study, the adsorption of crystal violet onto chitosan was investigated by looking into equilibrium, thermodynamics, and kinetic process. The adsorption experiments confirm that chitosan is effective for the adsorption of basic dye from aqueous solution. The results indicate that the Langmuir model describes the adsorption of crystal violet extremely well. The kinetic studies showed that the adsorption of chitosan followed pseudo - second order kinetics. The value of mean free energy E, evaluated by Dubinin Radushkevitch suggest that the process follows a chemical sorption process. The adsorption of crystal violet onto chitosan was dependent on solution $\mathrm{pH}$, contact time and initial dye concentration. The negative value of $\Delta \mathrm{G}^{\circ}$ confirms the spontaneous nature of the adsorption process. The positive $\Delta \mathrm{H}^{\circ}$ value confirmed the endothermic nature of the adsorption interaction, whereas the positive $\Delta \mathrm{S}^{\circ}$ value showed the increased randomness at the solid - solution interface during the adsorption process.

\section{References}

[1.] G.Thompson, J. Swai , M. Kay and C.F.Forster , The treatment of pulp and paper mill effluent - a review, Biores. Tech., 98, 2001, 275-286.

[2.] T. Robinson, G. McMullen G, R. Marchant, and P. Nigma, Remediation of dyes in textile effluent: a critical review on current treatment technologies with a proposed alternative, Biores. Tech., 77, 2001, 247-255.

[3.] M. Ali,and T.R. Sreekrishnan, Aquatic toxicity from pulp and paper mill effluents, a review, Adv. Envir., 5, 2001, 175-196.

[4.] D. Pokhrel, and T. Virraghavan, Treatment of pulp and paper mill waste water - a review, Sci. Total Envir,333, 2004, 37-58.

[5.] I.D. Mall, V.C. Sriuastava , N.K Agarwal , and I.M. Mishra, Removal of congo red from aqueous solution by bagasse fly ash and activated carbon: Kinetic study and equilibrium isotherm analyses. Chemo., 61, 2005, 499-501.

[6.] G.V. Franks, Stimulant sensitive flocculation and consolidation for improved solid / liquid separation, J.of Coll. and Int. Sci., 292, $2005,598-603$

[7.] Z.Aksu, Application of biosorption for the removal of organic pollutants a review. Pro. Biochem. ,40, 2005, 997-1026.

[8.] J.Synowieck, and N.A.Al Khateeb, Production, properties, and some new applications of chitin and its derivatives. Crit. Rev. Food Sci., N Utr 43, 2001,145-171.

[9.] M. Rinaudo , Chitin and chitosan - part I. Properties and application. Prog. Poly. Sci., 31, 2006, 603-632.

[10.] A. Martino A, P.G. Gifferi, and G. Spagna, Immobilization of $\beta$-glucosidase from a commercial preparation.Part 2. Optimization of the immobilization process on chitosan . Proc. Biochem., 31,1996, 287-293.

[11.] C. Grégorio, G. Frédéric, R. Capucine, M. Bernard M, A. Oliver,M.C. Nadia, D.G.Francois, and M.B. Pierre ,The removal of Basic blue 3 from aqueous solutions by chitosan - based adsorbent: Bach studies J. of Haz.Mat. ,153, 2008, 96-106.

[12.] K.S Tapan, C.B Nikhli, K. Subarna, G.A Mahmooda, I. Hidek, and F. Yoshinobu, Adsorption of Methyl Orange onto chitosan from aqueous solution. J. of Water Res. and Prot., 2, 2010, 898-906.

[13.] S .Zheng, Z. Yang, D.H.Jo, and Y.H Park, Removal of chlorophenols from ground water by chitosan sorption. Water. Res., 38, $2004,2315-2322$.

[14.] W .Li, Z .Junping, and W. Aiin, Removal of methylene blue from aqueous solution using chitosan -g- poly (acrylic acid) montmorillonite super adsorbent nanocomposite. Coll. and Surf A: Phy. Eng. Asp., 322, 2008, 47-53.

[15.] Saeed A, Sharif M, M Iqbal, Application potential of grapefruit peel as dye sorbet: Kinetics, equilibrium and mechanisms of crystal violet adsorption. J. of Haz. Mat.,179 (1-3), 2010, 564-572.

[16.] R .Ahmad, Studies and adsorption of Crystal violet dye from aqueous solution onto coniferous - pinus bark powder (CPBP). J.of Haarz.Mat., 171 (1-3), 2009, 767-773.

[17.] Q.Wu, Z .Shan, M .Shen, S.J.Li, and H.Chen, Biosorption of direct scarlet dye on magnetically modified Saccharomyces cerevisial cells. Chin. J. of Biotech. , 25 (10), 2009,1477-1482.

[18.] R.H Rodde, A. Einbu, and K.M Varum, A seasonal study of the chemical composition and chitin quality of shrimp shells obtained from northern shrimp. (Pandalus borealis). Carboh. Poly., 71, 2008, 388-393.

[19.] H.Struszczyk, Microcrystalline chitosan. Int. J. of Appl. Poly. Sci., 33, 1987, 177-189.

[20.] S .Rengaraj, M. Seung- Hyeon, and S. Sivabalm, Agricultural solid waste for the removal of organics: adsorption of phenol from water and wastewater by palm seed coat activated carbon. Was.Manag., 22, 2002, 543-548.

[21.] Z. K George,and K.L Nikolaos. Reactive and basic dyes removal by sorption onto chitosan derivates. J. of Coll. and Int. Sci., 331, 2009, 32-39.

[22.] B .Zehra, Ö. Coşan, S .Yoldaş, and Y .Kadir, Sorption of malachite green on chitosan bead. J.of Haz. Mat., 154, 2008, 254-261. 
[23.] G .Z Kyzas, and N.K Lazaridis, Reactive and basic dye removal by sorption onto chitosan derivatives. J. of Coll. and Int. Sci., 331, 2009, 32-39.

[24.] K .Azlan, W.N Wan SAIME, and L.L Ken, Chitosan and chemically modified chitosan beads for acid dyes sorption. J. of Envi.Sci., 21, 2009, 296-302.

[25.] P. Monvisade, and P. Siriphannon, Chitosan intercalated montmorillonite: Preparation, characterization and cationic dye adsorption. App. Clay. Sci., 42, 2009, 427-431.

[26.] A.C Chao, S.S Shyu, Y.C Lin, and F.L Mi, Enzymatic grafting of carboxyl groups onto chitosan - to confer on chitosan the property of a cationic dye adsorbent. Bior.Tech., 91, 2004, 157-162.

[27.] B. K Nandi, A. Goswami A, and M.K Purkait, Removal of cationic dyes from aqueous solutions by kaolin: Kinetic and equilibrium studies. Appl. Clay. Sci., 42, 2009, 583-590.

[28.] N. Barka, A. Assabbane, A. Nounah, L. Laanab, and Y. AitI chou, Removal of textile dyes from aqueous solutions by natural phosphate as a new adsorbent. Desal., 235, 2009, 264-275.

[29.] L.Yonghui, H. Yingbing, H. Guomin, T. Qijian, and H. Wenyong. Removal of crystal violet from aqueous solution using powdered mycelial biomass of ceriporia Lacerata P2. J. of Envi. Sci., 23 (12), 2011, 2055-2062.

[30.] A. Zhang, and Y. Fang, Adsorption orientations and interactions of methyl orange on negatively and positively charged colloidal silver particles. J. of Coll. and Int. Sci., 305, 2007, 270-274.

[31.] W.J. Weber and J.C. S Morris, Proceedings of International Conference on Water Pollution Symposium. 2, Pergamon, Oxford, , $1962,231-266$.

[32.] T .Akar, I. Tosun, Z. Kaynak, E .Ozkara, O. Yeni, and E.N Sahin, An attractive agro- industrial byproduct in environmental cleanup: Dye biosorption potential of untreated olive pomace. J. of Haz.Mat., 166 (2-3), 2009, 1217-1225.

[33.] W.T .Tsai, K.J. Hsien and J.M .Yang, Silica adsorbent prepared from spent diatomaceous earth and its application to removal of dye from aqueous solution. J. of Coll. and Int. Sci., 275 (2), 2004, 428-433.

[34.] M.S Chiou, and G.S Chuang. "Competitive adsorption of dye metanil yellow and RB15 in acid solutions on chemically cross linked chitosan beads." Chemosphere, 62, 2001, 731-740.

[35.] A.R .Cestari, E.F.S, Vieira, A.A .Pinto,and E.C.N. Lopes, Multiple adsorptions of anionic dyes on silica chitosan hybrid 1. Comparative Kinetic data from liquid - and - solid phase models. J. of Coll. Int. Sci. 292, 2005, 363-372.

[36.] D. Rita, N.N. Rao, S.P. Pande, and S.N Kaul, Removal of basic dyes from aqueous medium using a novel polymer Jalshaktr., Bio, Tech., 97, 2006, 877-885.

[37.] D. Mehmet, O.Yasemin, and A. Mahir, Adsorption, Kinetics and mechanism of cationic methyl violet and methylene blue dyes onto sepiolite. Dyes and Pig., 75, 2007, 701-713.

[38.] A.Mittal, J .Mittal, A. Malviya, D .Kaur, and V. K .Gupta, Adsorption of hazardous dye crystal violet from wastewater by waste materials. J. of Coll. Int. Sci., 343, 2012, 463-473.

[39.] H.M.F.Freundlich, Über die adsorption in lösungen, Zeitsdchrift für Physikalische Chemie, , 57, 1906, 385-470.

[40.] C.Aharoni, and D.L. Sparks, Kinetics of soil chemical process. A theoretical treatment. In Rates of Soil Chemical Processes DL. Sparks, D.L. Suarez (Eds). Soil Science Society of America, Special Publication, 1991, 27, (SSSA Madison, WI1-18.

[41.] M.M Dubinin, and L.V Radushkevitch, Equation of the characteristic curve of activated charcoal. Chem. Zentr, 1, 1947, 875.

[42.] B.T .Kim, H.K. Lee, H. Moon, and K.J. Lee, Adsorption of radionuclides from aqueous solutions by inorganic adsorbents. Sep.Purif. Tech., 30, 1995, 3165-3182.

[43.] S.L.Y Ling, C.Y.Yee, and H.S. Eng, Removal of a Cationic Dye using Deacetylated Chitin (Chitosan). J. of Appl. Sci., 11, 7, 2011, $1445-1448$.

[44.] G. Crini, C. Robert, F. Crimbert, B. Martel , O. Adam , and T. De Ciorgi, The removal of basic blue 3 from aqueous solutions by chitosan - based adsorbent: batch studies. J. of Haz. Mat., 153, 2007, 96-106.

[45.] U. Ilhan , and G. Fuat, Kinetics and thermodynamics of the adsorption of some dyestuffs, and p- nitrophenol by chitosan and MCM - Chitosan from aqueous solution. J .of Coll. and Int. Sci., 247, 2004, 398-412.

[46.] Y.S.Ho, T.H.Chiang,and Y.M.Hsueh, Removal of basic dye from aqueous solution using tree fern as a biosorbent. Proc. Bioch., 49, 2005, 119-124.

[47.] G. Annadurai, Adsorption of basic dye on strongly chelating polymer: Batch kinetic studies. Iran Poly., 11, 2002, 237-244.

[48.] G. Annadurai G, L.Y. Ling, and J.F. Lee, Adsorption of reactive dye from an aqueous solution by chitosan: isotherm, kinetic and thermodynamic analysis. J.of Haz. Mat., 159, 2008, 337-346.

[49.] S.M. Venkal, D.M. Indra , and C.S. Vimal, Use of bagasse fly ash as an adsorption for the removal of brilliant green dye from aqueous solution. Dye and Pig., 73, 2007, 269-278.

[50.] W.S. Wan Ngah, and S. Fatinathan , Chitosan flakes and chitosan GLA beads for adsorption of p- nitrophenol in aqueous solution.Coll. and Surf. A: Physi. and Eng.Asp., 277, 2006, 214-222.

[51.] R. Dolphen, N. Sakkayawong, P. Thiravetyan, and W. Nakbanpok, Adsorption of reactive red 141 from waste water onto modified chitin. J. of Haz., 143, 2007, 250-255.

[52.] W. Tang, C. Wang,and D. Chem, Kinetic studies on the pyrolysis of chitin and chitosan.Poly. Degra. and Stab., 87, 2005, 389-394.

Table 1: Physicochemical characteristics of chitosan

\begin{tabular}{|l|c|}
\hline Molecular formula & $\left(\mathrm{C}_{6} \mathrm{H}_{11} \mathrm{NO}_{4}\right) \mathbf{n}$ \\
\hline Formula weight & $\sim 160.9 \mathrm{gmol}^{-1}$ \\
\hline BET surface area & $131 \mathrm{~m}^{2} \mathrm{~g}^{-1}$ \\
\hline Pore volume & $0.108 \mathrm{~cm}^{3} / \mathrm{g}$ \\
\hline Moisture content \% & 1.25 \\
\hline Ash \% & 1.2 \\
\hline Solubility & $1 \% \mathrm{CH}_{3} \mathrm{COOH}$ \\
\hline Pka & 6.1 \\
\hline Color & Off-white \\
\hline Pore width & 13.8 \\
\hline Deacetylation & $85 \%$ \\
\hline
\end{tabular}


Basic Dye Adsorption On Low Cost Biopolymer: Kinetic And Equilibrium Studies

Table 2: Kinetic properties of CV adsorption onto chitosan at different concentrations

\begin{tabular}{|l|c|c|c|}
\multicolumn{1}{r}{ Kinetic parameters } & $\mathbf{2 5 0} \mathrm{ppm}$ & $\mathbf{1 5 0} \mathrm{ppm}$ & $\mathbf{7 5 p m}$ \\
\hline Pseudo-first order & & & \\
\hline $\mathrm{k}_{1}\left(\mathrm{~min}^{-1}\right)$ & $1.2 \times 10^{-3}$ & $6.6 \times 10^{-3}$ & $3 \times 10^{-3}$ \\
\hline $\mathrm{q}_{\mathrm{e}}(\mathrm{mg} / \mathrm{g})$ & 57.5 & 22.38 & 12.8 \\
\hline $\mathrm{R}^{2}$ & 0.90 & 0.89 & 0.88 \\
\hline Pseudo-second order & & & \\
\hline $\mathrm{k}_{2}(\mathrm{~g} / \mathrm{mg} \cdot \mathrm{min})$ & $7.7 \times 10^{-4}$ & $6.3 \times 10^{-4}$ & $2.2 \times 10^{-4}$ \\
\hline $\mathrm{q}_{\mathrm{e}}(\mathrm{mg} / \mathrm{g})$ & 56 & 24 & 22 \\
\hline $\mathrm{R}^{2}$ & 0.98 & 0.98 & 0.99 \\
\hline Intraparticle Diffusion & & & \\
\hline $\mathrm{k}_{\mathrm{p}}\left(\mathrm{mg} \mathrm{min}^{0.5} / \mathrm{g}\right)$ & 1.5 & 1.4 & 0.7 \\
\hline $\mathrm{C}$ & 1.8 & 1.4 & 1 \\
\hline $\mathrm{D}\left(\mathrm{m}^{2} / \mathrm{min}\right)$ & $6.2 \times 10^{-18}$ & $2.16 \times 10^{-18}$ & $0.63 \times 10^{-18}$ \\
\hline $\mathrm{R}^{2}$ & 0.99 & 0.98 & 0.99 \\
\hline
\end{tabular}

Table 3: Summary of Isotherm constants for CV onto Chitosan.

\begin{tabular}{|c|c|c|c|}
\hline & \multicolumn{3}{|c|}{ Temperature (K) } \\
\hline Langmuir isotherm constant & 293 & 313 & 323 \\
\hline $\mathrm{Q}_{0}(\mathrm{mg} / \mathrm{g})$ & 19.23 & 20 & 28.5 \\
\hline $\mathrm{K}_{\mathrm{L}}(\mathrm{L} / \mathrm{mg})$ & 0.346 & 0.83 & 0.413 \\
\hline $\mathrm{R}^{2}$ & 0.988 & 0.99 & 0.99 \\
\hline \multicolumn{4}{|l|}{ Freundlich isotherm constant } \\
\hline $\mathrm{K}_{\mathrm{F}}(\mathrm{mg} / \mathrm{g})$ & 5.01 & 1.2 & 3.16 \\
\hline $\mathrm{n}$ & 2.5 & 3.6 & 1.85 \\
\hline $\mathrm{R}^{2}$ & 0.92 & 0.89 & 0.91 \\
\hline \multicolumn{4}{|l|}{ Tempkin constants } \\
\hline $\mathrm{A}(\mathrm{L} / \mathrm{mg})$ & 2.7 & 1.3 & 1.2 \\
\hline B & 606 & 369 & 215 \\
\hline $\mathrm{R}^{2}$ & 0.94 & 0.92 & 0.93 \\
\hline \multicolumn{4}{|l|}{ D-R constants } \\
\hline $\mathrm{q}_{\mathrm{s}}(\mathrm{mg} / \mathrm{g})$ & 71 & 95.7 & 166 \\
\hline $\mathrm{B}\left(\mathrm{mol}^{2} / \mathrm{J}\right)$ & 0.067 & 0.083 & 0.096 \\
\hline $\mathrm{E}(\mathrm{KJ} / \mathrm{mol})$ & 14.9 & 12 & 10 \\
\hline $\mathrm{R}_{D R}^{2}$ & 0.94 & 0.96 & 0.93 \\
\hline
\end{tabular}

Table 4: Thermodynamic parameters for adsorption of CV onto chitosan $\left(\mathrm{C}_{\mathrm{o}}=100 \mathrm{ppm}\right)$

\begin{tabular}{|c|c|c|c|}
\hline Temperature (K) & $\square \mathbf{H ~ ( k J / m o l )}$ & $\square \mathbf{S}(\mathbf{J} / \mathbf{m o l ~ K})$ & $\square \mathbf{G}(\mathbf{k J} / \mathbf{m o l})$ \\
\hline 293 & & & -28.84 \\
\hline 313 & 47.5 & 254 & -33.09 \\
\hline 323 & & & -32.27 \\
\hline
\end{tabular}

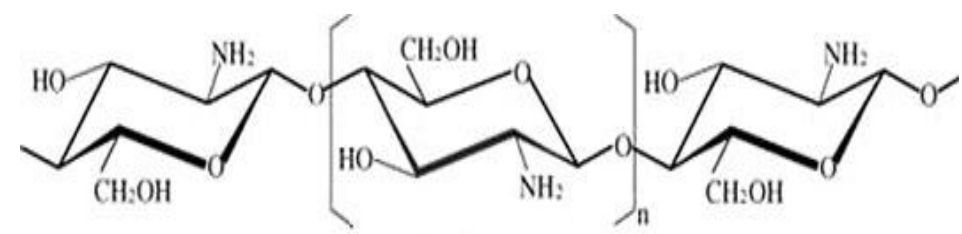

Chitosan

Figurel: Chemical Structure of Chitosan 


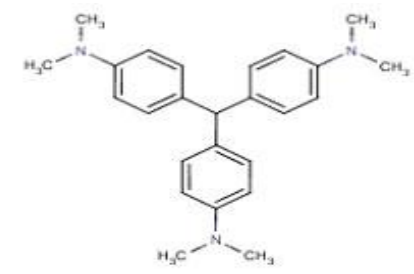

Figure 2: Chemical Structure of Crystal violet

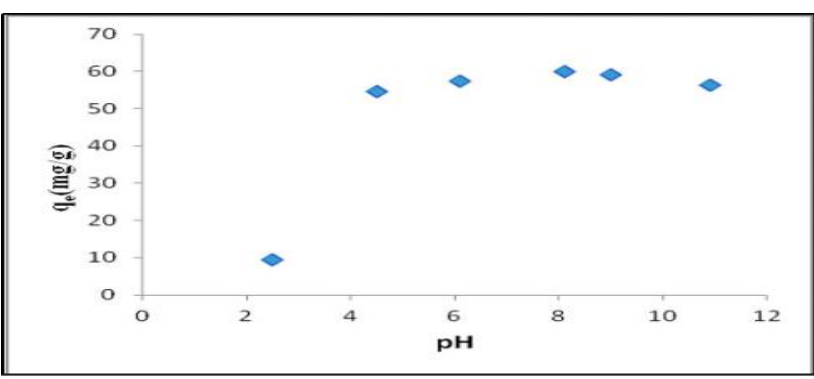

Figure 3: E ffect of $\mathrm{pH}$ on adsorption of $\mathrm{CV}$ onto chitosan

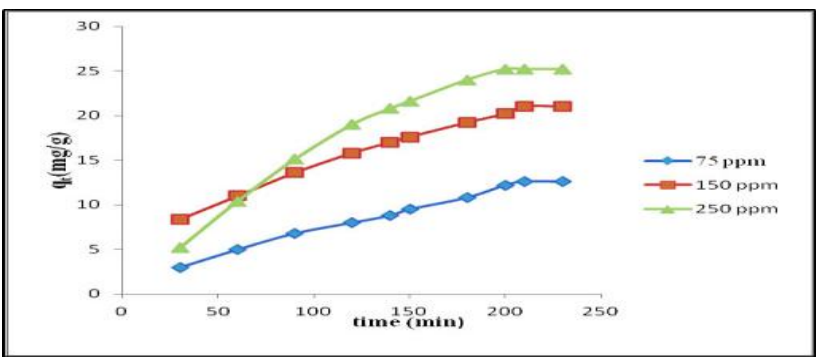

Figure 4: Effect of contact time and initial dye concentration onto chitosan

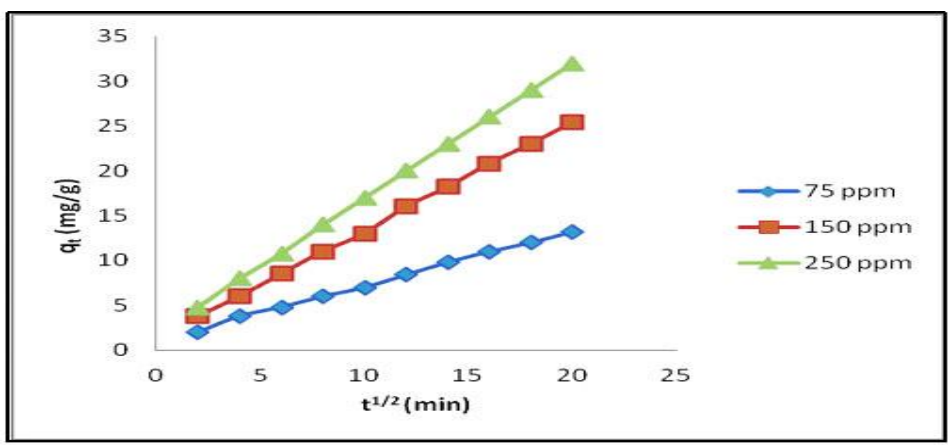

Figure 5: Effect of intraparticle diffusion on the ads orption of crystal violet

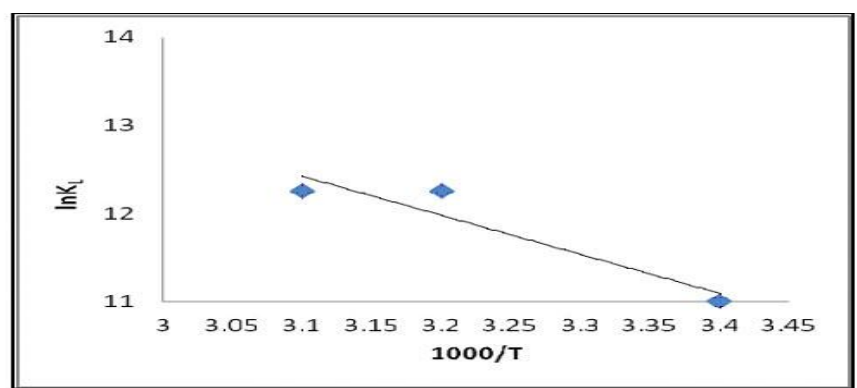

Figure 6: Arrhenius plot of crystal violet onto chitosan 


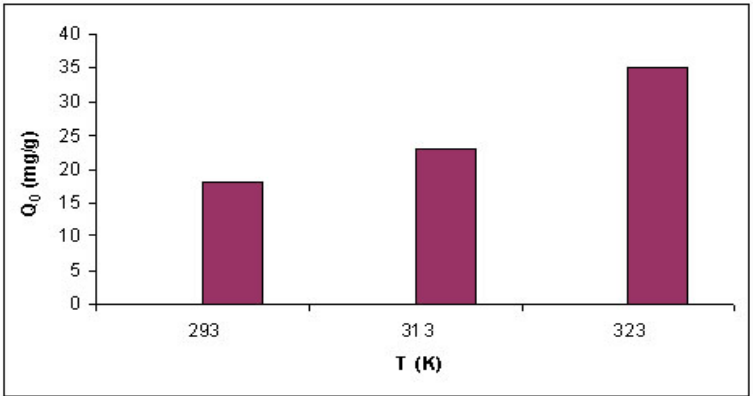

Figure 7. Effect of temperature on adsorption cap acity of crystal violet onto chitosan.

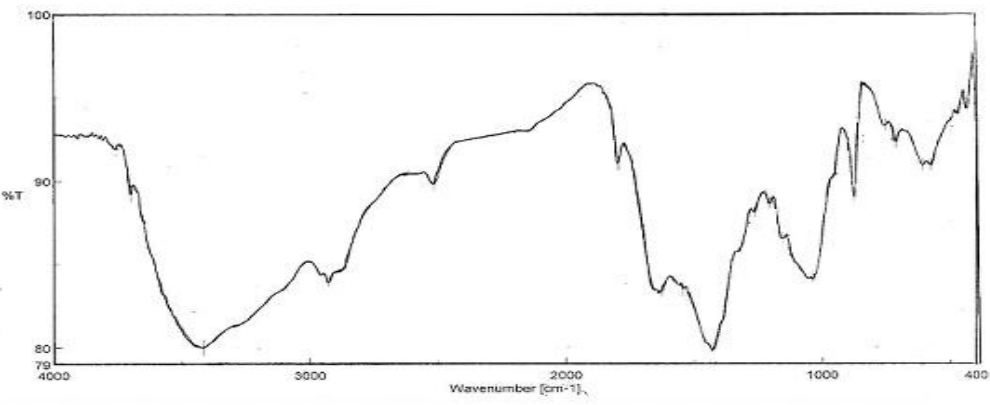

Figure 8: FTIR of chitosan

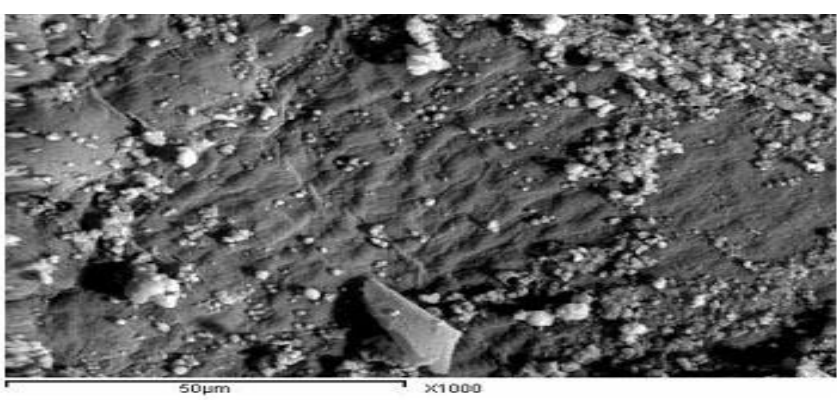

Figure 9: SEM of chitosan
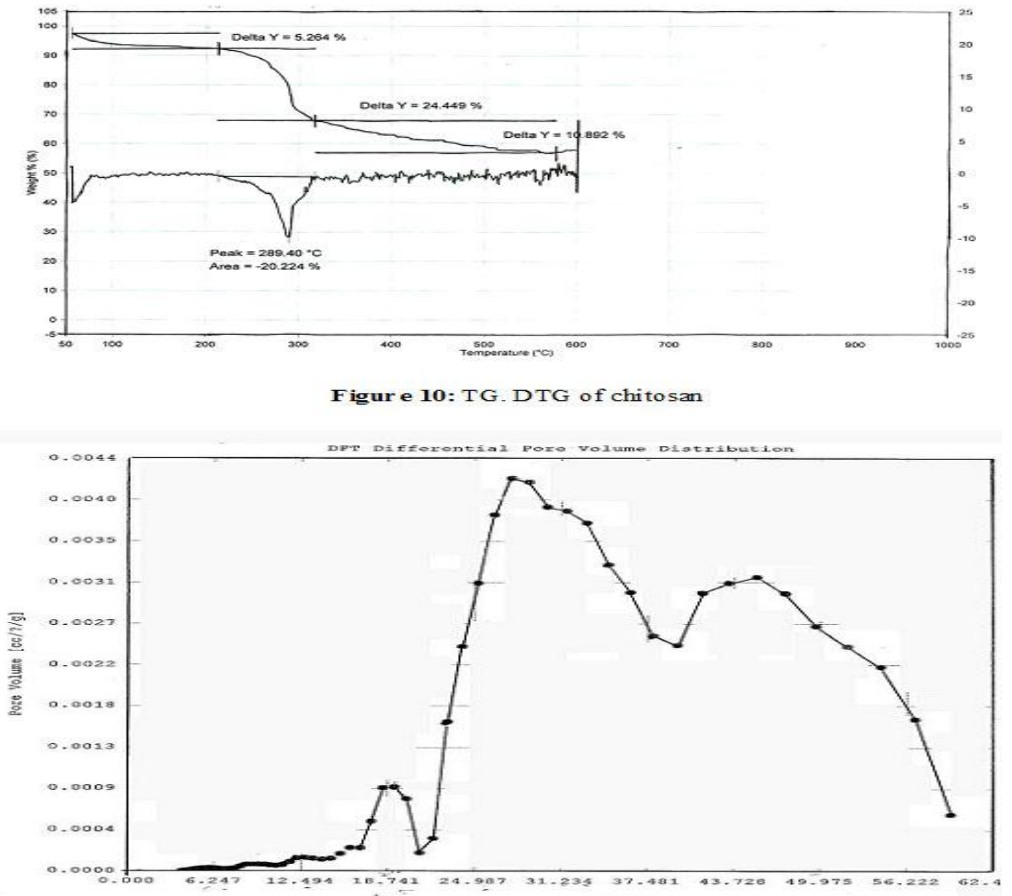

Figure I1 : Particle size distribution of chitosan 